\title{
Research on the Impact of Reducing Industrial and Commercial Electricity Price on Henan's Overall Price Level—Based on Social Accounting Matrix
}

\author{
Yanming Jin ${ }^{1,3}$, Zhuonan $\mathrm{Li}^{1}$,Mingyang Zhang ${ }^{2}$ \\ ${ }^{1}$ State Grid Energy Research Institute, Beijing 102209, PRC. \\ ${ }^{2}$ China University of Petroleum, Beijing 100083, PRC.
}

\begin{abstract}
In order to reduce the operating costs of enterprises and optimize the business environment, China implemented the policy of reducing the general industrial and commercial electricity price by $10 \%$ in 2018 and 2019. This study uses the social accounting matrix to evaluate the effect of policy implementation on the price level of Henan Province. Through price transmission, we analyze the impact of industrial and commercial electricity price changes on production price and consumer price fluctuation of other sectors. The results show that the adjustment of general industrial and commercial electricity price has limited effect on the overall economic price level of Henan Province. The impact of electricity price adjustment on urban consumer price index is higher than that of rural consumer price index.
\end{abstract}

\section{Introduction}

In order to implement the policy of reducing the general industrial and commercial electricity price, Henan Province has reduced the general industrial and commercial electricity prices three times in 2018 . For the first time, 0.533 points $/ \mathrm{kWh}$ was reduced, the second time was reduced by 0.55 points $/ \mathrm{kWh}$, and the third time was reduced by 6.24 points $/ \mathrm{kWh}$. The total price of the general industrial and commercial catalogue was reduced by 7.32 points $/ \mathrm{kWh}$. Henan province has completed the goal of cutting down the industrial and commercial electricity prices by $10 \%$, which has directly reduced the cost of electricity for industrial and commercial users, which almost amount to 4 billion yuan.

Reducing the general industrial and commercial electricity prices mainly involves the operating costs of small and medium-sized enterprises, with a wide range and high social attention. The effect of this policy on the expansion of domestic demand, consumption, and industrial upgrading in Henan Province needs further evaluation. Based on the Input-Output Table of Henan, this paper constructs the Social Accounting Matrix (SAM) of Henan Province. Through the analysis of price multiplier and conduction path, we conduct quantitatively research on the effect of reducing the general industrial and commercial electricity price on Henan's overall economic price level.

\section{The review}

At present, three methods for analyzing the impact of electricity price on the economy are namely the inputoutput model, the social accounting matrix (SAM) and the commutable general equilibrium (CGE)analysis, which are now widely used. The input-output model is used to analyze the impact of rising energy prices on various economic sectors in Mexico[1]. Combined with the Social Accounting (SAM) to assess the influence of rising electricity prices in Turkey on producers and consumers, it is found that the energy production industry, the coal industry, and the steel industry are affected more than other production industries, while consumers are affected lower than the production sector[2]. The results show that from the perspective of industry, the adjustment of electricity prices has the greater impact on the electrical equipment manufacturing industry and the petrochemical industry. CGE is regarded as the main analytical method, which is the basis of quantitative analysis. Some researches use it to analyze the impact of rising electricity and oil prices on the economy, and make the concrete analysis of the four categories, which is production, consumption, households with different incomes and government[3]. Some studies simulate the interaction among the sectors of the national economic system, and analyze the impact of electricity price adjustment on the development of the national economy[4]. Considering its dynamic randomness, some literature has been revised the general equilibrium model, and discussed the impact of power price fluctuations on the variables such as

\footnotetext{
3 jinyanming@sgeri.sgec.com.cn
} 
economic growth and price level from microscopic perspective[5].

Except for the above-mentioned commonly used methods, there are the studies who consider the impact of electricity price adjustment on the economy from other angles. The research takes Chongqing as an example to discuss the impact of price changes on the demand side, and conducts quantitative analysis of the impact of electricity prices on the local economy from the two indicators, namely output electricity rate and price increase rate[6]. Some researchers use unit root test, cointegration test and regression analysis to analyze the effect and extent of electricity price fluctuation on different regional economies, which are based on the historical data of electricity price, PPI and CPI of different provinces[7]. Others use vector error correction model to analyze the relationship between electricity price fluctuation and the overall price index [8].

\section{The model}

\subsection{The Structure of Social Accounting Matrix}

The social accounting matrix is based on the input-output table and uses the matrix situation to reflect the income and expenditure of various accounts in the economic system. The row data reflect the income of one account (such as product sector, residents, government, etc. ) and the column represent the expenditure of another account, which the total income of each account is equal to the total expenditure.

Table1. The structure of SAM

\begin{tabular}{c|cccccc|c}
\hline \multicolumn{2}{c}{} & I & II & III. & IV. & V. & \multicolumn{2}{c}{ VI. } & VII.Total \\
\hline I. Product sector & $T_{11}$ & $O$ & $T_{13}$ & $T_{14}$ & $T_{15}$ & $T_{16}$ & $Y_{1}$ \\
II. Element (labor force, capital) & $T_{21}$ & $O$ & $O$ & $O$ & $O$ & $O$ & $Y_{2}$ \\
III. Residents (urban, rural) & $O$ & $T_{32}$ & $T_{33}$ & $T_{34}$ & $O$ & $O$ & $Y_{3}$ \\
IV. Government (local, central) & $T_{41}$ & $O$ & $T_{43}$ & $O$ & $O$ & $O$ & $Y_{4}$ \\
V. Other areas & $T_{51}$ & $T_{52}$ & $O$ & $O$ & $O$ & $O$ & $Y_{5}$ \\
VI. Capital accumulation & $O$ & $O$ & $T_{63}$ & $T_{64}$ & $T_{65}$ & $O$ & $Y_{6}$ \\
\hline VII. Total & $Y_{1}$ & $Y_{2}$ & $Y_{3}$ & $Y_{4}$ & $Y_{5}$ & $Y_{6}$ & \\
\hline
\end{tabular}

\subsection{Calculation of price multiplier}

To measure the impact of the sector's price fluctuation caused by exogenous shocks on other sectors' commodity prices, we define the price multiplier of the sector $i$ to the sector $\mathrm{j}$ based on the concept of investment multiplier in Keynesian model. The price changes of sector $\mathrm{j}$ with the price fluctuation of sector $\mathrm{i}$ can be expressed by the following formula:

$$
\frac{d p_{j}}{d v_{i}}=m_{i j}
$$

In the above formula, $v_{i}$ represents the price of the sector with an exogenous shock, $p_{j}$ represents the comprehensive product price of sector $j$, and $m_{i j}$ is the price multiplier.

In price multiplier analysis, the accounts in SAM table are divided into endogenous accounts and exogenous accounts. In Table $2, n_{1}, n_{2}$ and $n_{3}$ represent the number of sectors in each category. We merge all the exogenous sectors into one account (including $n_{4}$ sectors), and assume that the exogenous shocks in the economy originate from exogenous accounts and act on endogenous accounts, which directly lead changes in the costs and prices of the corresponding endogenous sectors.

Table 2. The structural schematic diagram of SAM

\begin{tabular}{c|cccc|c}
\hline & I. & II. & III. & IV. & V. Total \\
\hline I. Product sector(commodity, Multi-sector, $\left.n_{1}\right)$ & $T_{11}$ & $O$ & $T_{13}$ & $T_{14}$ & $Y_{1}$ \\
II. Production sectors (labor force, capital, $n_{2}$ ) & $T_{21}$ & $O$ & $O$ & $O$ & $Y_{2}$ \\
III. Residents (urban, rural, enterprise, $n_{3}$ ) & $O$ & $T_{32}$ & $T_{33}$ & $T_{34}$ & $Y_{3}$ \\
IV. Others (government, Capital accumulation, etc, $n_{4}$ ) & $T_{41}$ & $T_{42}$ & $T_{43}$ & $T_{44}$ & $Y_{4}$ \\
\hline V. Total & $Y_{1}$ & $Y_{2}$ & $Y_{3}$ & $Y_{4}$ & \\
\hline
\end{tabular}

Assuming that the price of the product is entirely determined by the production cost and irrelevant to output level, which means under the condition that the return to scale is constant, the manufacturer would not change the relative proportion of the input when the relative price of input changes little. Note $P_{i}=\left(P_{i 1}, P_{i 2} \cdots P_{i, n 1}\right)$ is the price index of endogenous account $i$ and $\pi_{4}=\left(\pi_{41}, \pi_{42} \cdots \pi_{4, n 4}\right)$ is the price index of exogenous 
account. Note $A_{i j}=\frac{T_{i j}}{Y_{j}}$ as the element of SAM matrix after standardization. Then, columns 1, 2 and 3 of SAM table can be obtained respectively:

$$
\begin{aligned}
& p_{1}=p_{1} A_{11}+p_{2} A_{21}+\pi_{4} A_{41} \\
& p_{2}=p_{3} A_{32}+\pi_{4} A_{42} \\
& p_{3}=p_{1} A_{13}+p_{3} A_{33}+\pi_{4} A_{43}
\end{aligned}
$$

The above three equations reflect the price determination process of various accounts. For example, for the commodity production sector, the product price $p_{1}$ is the cost of the intermediate $\operatorname{input}\left(p_{1} A_{11}\right)$ and the factor cost ( $p_{2} A_{21}$, which is the product added value part, including wages, capital costs and land rents) plus other costs such as direct government taxes, the cost of imported goods, etc. $\left(\pi_{4} A_{41}\right) . p_{3}$ actually reflects the living cost index of residents, which is the average index $\left(p_{1} A_{13}\right)$ of households' consumption of various commodities by value, and may also include mutual transfer payments between residents ( $p_{3} A_{33}$ ), plus the various indirect taxes imposed by the government on residents, such as income $\operatorname{tax}\left(\pi_{4} A_{43}\right)$.

Define a standardized coefficient matrix A as:

$$
A=\left[\begin{array}{ccc}
A_{11} & 0 & A_{13} \\
A_{21} & 0 & 0 \\
0 & A_{32} & A_{33}
\end{array}\right]
$$

And note is the price vector for all the endogenous sectors of SAM matrix, $\quad v=\pi_{4} A(4) \quad$,among them:

$A(4)=\left(A_{41}, A_{42}, A_{43}\right)$ then

$P=P A+v=v(I-A)^{-1}=v M$

$M$ is the multiplier matrix, $m_{i j}=d p_{j} / d v_{i}$. Since $M$ is also the quantity multiplier in the income determination model, $M^{\prime}$ is called the price multiplier matrix for the purpose of differentiation, and element $m_{j t}{ }^{\prime}$ in $M^{\prime}$ represents the ratio of the price change of sector $j$ and the price change of sector $i$ when the price (cost) of sector $i$ changes.

\section{The analysis of result}

Based on the Henan's Input-Output table in 2012, this paper compiles the Henan's Social Accounting Matrix, which include 42 production sectors, 5 production factors (three labors: agricultural labor, production workers, technicians, capital and land), urban and rural Residents. According to the price classification carried out by various sectors, the SAM table focuses on the impact of the general industrial and commercial sectors such as wholesale and retail, leasing and business services and the overall economic development level of Henan province.

According to the industrial and commercial electricity price level in Henan Province and the electricity consumption of the industrial and commercial sectors, the proportion of electricity expenses in the following sectors is calculated as the proportion of cost expenditure. Among them, the cost of electricity expenses in the wholesale and retail sectors is relatively high.

Table3. The proportion of electricity expenses before and after price adjustment in the Main Sectors

\begin{tabular}{c|c|c|c}
\hline Sectors & $\begin{array}{c}\text { The proportion of electricity } \\
\text { cost before the price adjustment }\end{array}$ & $\begin{array}{c}\text { The proportion of electricity } \\
\text { cost after the price adjustment }\end{array}$ & $\begin{array}{c}\text { The } \\
\text { change }\end{array}$ \\
\hline $\begin{array}{c}\text { Wholesale and retail } \\
\begin{array}{c}\text { Transportation, warehousing and } \\
\text { postal service }\end{array}\end{array}$ & $13.4 \%$ & $12.1 \%$ & $1.3 \%$ \\
\hline Accommodation and catering & $2.7 \%$ & $2.4 \%$ & $0.3 \%$ \\
\hline $\begin{array}{c}\text { Information transmission, software } \\
\text { and information technology services }\end{array}$ & $1.7 \%$ & $1.5 \%$ & $0.2 \%$ \\
\hline financial & $4.7 \%$ & $4.2 \%$ & $0.5 \%$ \\
\hline The real estate & $0.5 \%$ & $0.4 \%$ & $0.1 \%$ \\
\hline Leasing and business services & $9.6 \%$ & $8.6 \%$ & $1.0 \%$ \\
\hline $\begin{array}{c}\text { Scientific research and technical } \\
\text { services }\end{array}$ & $4.4 \%$ & $4.0 \%$ & $0.4 \%$ \\
\hline
\end{tabular}

According to Table 3, reducing the electricity price of general industrial and commercial enterprises, it is preliminarily estimated that the average cost of wholesale and retail industry in Henan province decreases about $1.3 \%$. Second, the average cost of real estate, information transmission, software and information technology services and transportation decreased by about $1.0 \%, 0.5 \%$ and $0.3 \%$ respectively. Based on the price multiplier of the corresponding sectors, assuming that the cost changes of electricity expense of the above-mentioned sectors can be fully transmitted, the final decline of the production price index of Henan province will be about $0.078 \%, 0.080 \%$, $0.060 \%$ and $0.045 \%$ respectively, and the decline of the consumer price index will be about $0.078 \%, 0.16 \%$, $0.0075 \%$ and $0.039 \%$ respectively. 
Table4. Price multiplier for general industrial and commercial sectors in Henan province

\begin{tabular}{|c|c|c|c|c|c|c|c|}
\hline & $\mathbf{a}$ & $\mathbf{b}$ & c & d & e & $\mathbf{f}$ & g \\
\hline Transportation (a) & 1.13 & 0.10 & 0.03 & 0.12 & 0.06 & 0.04 & 0.02 \\
\hline $\begin{array}{c}\text { Information transmission, } \\
\text { computer services and software(b) }\end{array}$ & 0.00 & 1.01 & 0.00 & 0.01 & 0.00 & 0.00 & 0.00 \\
\hline Wholesale and retail trade(c) & 0.03 & 0.04 & 1.04 & 0.02 & 0.02 & 0.04 & 0.01 \\
\hline Accommodation and catering(d) & 0.15 & 0.34 & 0.07 & 1.06 & 0.07 & 0.05 & 0.01 \\
\hline Financial insurance(e) & 0.05 & 0.06 & 0.03 & 0.06 & 1.04 & 0.04 & 0.02 \\
\hline The real estate industry(f) & 0.03 & 0.03 & 0.02 & 0.02 & 0.02 & 1.02 & 0.03 \\
\hline Leasing and business services(g) & 0.03 & 0.07 & 0.02 & 0.05 & 0.05 & 0.05 & 1.02 \\
\hline Scientific research & 0.01 & 0.02 & 0.01 & 0.02 & 0.01 & 0.01 & 0.00 \\
\hline $\begin{array}{c}\text { education } \\
\end{array}$ & 0.04 & 0.04 & 0.03 & 0.03 & 0.04 & 0.03 & 0.01 \\
\hline $\begin{array}{c}\text { Health, social security and social } \\
\text { welfare }\end{array}$ & 0.02 & 0.03 & 0.01 & 0.02 & 0.03 & 0.02 & 0.00 \\
\hline Culture, sports and entertainment & 0.01 & 0.02 & 0.00 & 0.01 & 0.02 & 0.01 & 0.00 \\
\hline $\begin{array}{c}\text { Public administration and social } \\
\text { organization }\end{array}$ & 0.00 & 0.01 & 0.00 & 0.00 & 0.01 & 0.01 & 0.00 \\
\hline Rural consumer price index & 0.18 & 0.10 & 0.05 & 0.09 & 0.36 & 0.10 & 0.01 \\
\hline Urban consumer price index & 0.27 & 0.38 & 0.10 & 0.22 & 0.53 & 0.25 & 0.06 \\
\hline Producer price index & 0.15 & 0.12 & 0.06 & 0.09 & 0.16 & 0.08 & 0.03 \\
\hline Consumer price index & 0.13 & 0.15 & 0.06 & 0.14 & 0.24 & 0.16 & 0.09 \\
\hline
\end{tabular}

\section{The conclusion}

The adjustment of general industrial and commercial electricity price has the limited effect on the overall economic price level adjustment in Henan Province. Due to the relatively low proportion of electricity expenditure in these industrial and commercial sectors like wholesale, retail trade, transportation, warehousing industry and information technology service industry in Henan Province, we reduce the general industrial and commercial electricity price by $10 \%$ on average, which makes the cost expenditure of the above-mentioned sectors decrease by about $1 \%$. Assuming that the change of electricity price cost in the above-mentioned sectors can be fully transmitted, the model shows that Henan's production price index declines by about $0.078 \%$.

General industrial and commercial electricity price adjustment has the higher impact on urban consumer price index than rural consumer price index. Under the background of the adjustment of electricity price in general industrial and commercial sectors, urban consumer price index is more likely to be affected than rural residents, and the overall production price level in Henan province is more susceptible than social consumer price level as well.Considering that information transmission, information technology service industry and real estate are the direct consumption sectors of urban and rural residents, so the consumer price index is more affected by the electricity price adjustment of general industrial and commercial sectors than the change of production price index. In addition, the adjustment range of consumer price index of urban residents is much larger than consumer price index of rural residents.

The effects of direct and indirect price adjustments require overall assessments.Reducing the level of general industrial and commercial electricity prices is not only to affect the direct costs of above-mentioned sectors, but also affect many aspects, such as the prices of other consumer goods and the income of residents. Based on analysis, in the process of cost transmission in the industrial and commercial sectors, some are transmitted through direct channels while some cost effects may emerge from multiple paths, and it is these indirect effects that account for a large proportion. To conduct policy analysis, the direct impact of price adjustments needs to be considered, as well as the indirect effects.

\section{Acknowledgement}

This research was funded by the State Grid Corporation's science and technology project "Research on Technology Route and Application Policy of Promoting ReElectrification".

\section{References}

1. Uri N D, Boyd R. An evaluation of the economic effects of higher energy prices in Mexico[J]. Energy Policy, 1997, 25(2):205-215.

2. Akkemik, Ali K. Potential impacts of electricity price changes on price formation in the economy: a social accounting matrix price modeling analysis for Turkey[J]. Energy Policy, 2011, 39(2):854-864.

3. Lim S Y, Yoo S H. The impact of electricity price changes on industrial prices and the general price level in Korea[J]. Energy Policy, 2013, 61:1551-1555.

4. Lim S Y, Yoo S H. The impact of electricity price changes on industrial prices and the general price level in Korea[J]. Energy Policy, 2013, 61:1551-1555. 
5. Miroslav Verbič, Sanja Filipović, Mirjana Radovanović.Electricity prices and energy intensity in Europe[J].Utilities Policy, 2017, 47: 58-68.

6. Jin yan-ming,Lei ming. Sectoral Growth and Poverty Alleviation - - A Multiplier Decomposition Technique Applied to GuiZhou Province[J]. Journal of ShanXi Finance and Economics University,2006,28(4):30-34.

7. ZHAO Hui-ru,YOU Pei-pei. The Impact of Electricity Price Adjustment on National Economy based on SAM Multiplier Analysis[J]. The 2008 International Conference on Risk Management \& Engineering Management,339-343.

8. He Y X, Zhang S L, Yang L Y, et al. Economic analysis of coal price-electricity price adjustment in China based on the CGE model[J]. Energy Policy, 2011, 38(11):6629-6637. 